\title{
From the Machine Paradigm to Brain Plasticity and How Culture Overrules Biology in Humans
}

\author{
Arnulf Kolstad ${ }^{1,2}$ \\ ${ }^{1}$ Norwegian University of Science and Technology, Trondheim, Norway \\ ${ }^{2}$ Hangzhou Normal University, Hangzhou, China \\ Email: arnulf.kolstad@svt.ntnu.no
}

Received May $28^{\text {th }}$, 2012; revised June $29^{\text {th }}$, 2012; accepted July $27^{\text {th }}, 2012$

\begin{abstract}
This paper emphasises how higher psychological functions develop dialectically from a biological basis and how the brain changes with mental and physical activity in a specific culture due to its plasticity. A scientific psychology cannot ignore that human consciousness exists. Humans' higher psychological functions, their language and thinking, have to be the core of human psychology. The psychological functions cannot be dissolved into biological, neurological processes. The number of human activities under biological control is greatly reduced in comparison to (other) animals. The higher psychological phenomena are humanly constructed as individuals participate in social interaction in a specific culture and are therefore cultural dependent. To understand how biology, culture and mind is dialectical related is crucial for a reasonable psychological epistemology.
\end{abstract}

Keywords: Brain Plasticity; Mind; Consciousness; Biology; Culture; Epistemology

\section{Introduction}

A significant problem for an understanding of human psychology is to clarify the mind/brain relationship and how biology, culture and mind are related. Due to the complexity of the phenomenon and the possibilities of choosing different perspectives makes it understandable that there are disagreement and multiple explanations of the same phenomenon. Competition and debates will never vanish in science, and a real discussion about theories, explanations and methods is necessary and desirable in every science.

As human beings we develop ontogenetically from a biological organism to cultural persons. We are permanently changing and influencing each other, qualities are transformed, reshaped and new patterns or configurations are created all the time, both in the mind and in the brain. Separate elements which intervene create new elements, functions and phenomena and they are again influencing each other. Old functions or elements are still part of a human being, but they have changed to another form, with another meaning and signification. New concepts and activity develop our understanding and this psychological activity also changes the brain by establishing new connections between neurons due to the brain's plasticity. The words mean different things at different ages and with altered experiences. The words enter into new connections and our knowledge and understanding changes in accordance. The brain has to adapt to the elaboration of the mind and change its structure and function to represent the altering and developing mind. The "machine paradigm" which has been a dominating approach to the human brain cannot explain this transformation and has therefore been under attack in recent decades. The comprehension of the humans as a machine and the brain as a computer excludes the possibility for human beings to take an effective part in its own development, and it therefore cast out of science any self-determination approach and also conscious- ness as something different from automatic reactions.

A human being is constantly creating (new) meaning to sense impressions. To create new meaning is also a human quality we do not find in a machine or in other animals to the same degree. Humans are born with an ability to create new knowledge, not only to repeat what is already known. Both the repetitive ability and the creative ability are necessary for human survival and the creative ability is impossible to replicate in an objective or mechanical way. Creativity is subjective based on individual experience (Vygotsky, 1990) and cannot be simulated in a machine.

\section{Perception $=$ Sense Impression + Cognition}

What is called perception in humans cannot be simulated by a machine or a computer (Kohler, 2010). Perception, giving meaning to sense impressions, is a fundamental capacity of humans; it represents the relationship to the "outside" world. The subjective reactions on the sense stimuli received from the outside and the verbal communication with other human being create the "inner" psychology of every individual, different from each other and with similarities in the same culture.

The human brain is not made for objective registration. The experience of a sense impression depends on the context, former experiences and expectations just now. The same sense impression therefore can give different experiences from time to time and definitely from person to person. People evaluating the same sense impression in psychophysical studies do not see or hear the same. They very naturally interpreting or processing the same sense stimulus, for instance a colour or a sound, in different manners and give it different meaning, depending on their subjective, personal experience stored in their memory. This is necessary and natural. This fact was actually looked upon as a problem by some (machine) psychologists at the turn of the 20th century, and introspection, or subjective experience, 
was declared non-scientific. But introspection has to be at the core of every psychological methodology. It tells what people actually feels, thinks and do, the main subjects in human psychology.

\section{Contradictions and Inter-Functionality}

The machine paradigm and the non-dialectical way of thinking is a typical Western way of reason, emphasizing a simple, deterministic world, focusing on salient objects instead of the larger picture. In this Western epistemology there is a prohibittion against contradiction (Kolstad, 2011). There is no place for quantitative development creating qualitative changes. The East Asians on the other hand believe in constant change and contradictions, searching for relationships and cannot understand the part without understanding the whole. Confucians believed, far more than the intellectual descendants of Aristotle, in the malleability of human nature. The world was simply too complex and interactive for categories and rules to be helpful for understanding objects and controlling them according to the East Asian philosophers and scholars. Contemporary human sciences have inherited the Western focus on isolated single elements not submitted to the whole, and the variables representing the isolated elements are knit together in a mechanical or additive way by multivariate statistics in research. To gain knowledge about complex living organisms by treating them and their context this way gives as Kohler (2010) writes "a distorted knowledge about real human beings”.

One of the founding fathers of sociology and social psychology, Auguste Comte, said explicitly that the understanding of nature, society and human beings that means the work in all sciences, had to pass through three stages; 1 ) the theological, 2) the metaphysical, and 3) the scientific (positive). To the last of these he also gave the name 'positive', and he said that the social sciences and psychology could be scientific by treating social and psychological phenomena as objective "thing". The 'positive stage' was introduced by Comte in his Cours de philosophie positive, published in six volumes between 1830 and 1842. In Comte's (1853/2009) historical reconstruction, the positive state has completed the development of human mind and human history by overcoming the previous theological and metaphysical ones. The positive philosophy regarded all phenomena as subjected to invariable natural laws and its task was to discover these natural laws. Though there was no place for psychological knowledge of subjectivity in Comte's positivist system, psychology nevertheless adopted the positivist framework in which positive was identified with the scientific, and scientific with the discovery of natural laws. Comte is best known for his assertion that social phenomenon can be studied by the same methods as used in natural science since there are general laws existing in all sciences, and the aim for the researchers is to reveal them by "positivistic" methods. The social sciences and psychology could be scientific by treating social and psychological phenomena as "thing". Linear mathematics and statistics also become tools for the social sciences in the struggle to become scientific and be accepted. Today the socalled "evidence based methods", resting on a simple causeeffect dichotomy and with the randomized controlled experiment as the gold standard, maintain a particular epistemology in the human sciences and contribute to the machine paradigm. This is representing a mechanistic way of constituting a human being and not a dialectical or "organic” way (Kohler, 2011).
The machine has been not only the metaphor, but the model. The human sciences have adapted the empirical strait jacket borrowed from the old natural sciences, and the modern drill in mathematical statistics.

There is however, a distinction between the "machine paradigm" and the "natural scientific paradigm". To criticize the machine as a model for humans does not imply that psychology should not be inspired by recent natural sciences, both their theories and methods. Theory of relativity and "chaos" theory are both different from the Newtonian deterministic mechanics, and especially chaos theory underlines a particular kind of indetermination (Kolstad, 2011).

\section{The Computer Metaphor and Brain Plasticity}

The analogy between a computer and the human brain became fashionable with cognitive psychology in the 1980s and neurobiology/neuropsychology and brain research in the 1990s ("Decade of the brain"). The human brain was comprehended as a computer's hardware; it didn't change. Today we know that the brain is more like a computer's software since it due to its plasticity is changing as a result of being used. That human beings are able to change themselves is an important aspect making up the difference between inert and alive human entities.

\section{Evolutionary and Cultural Approach}

Two perspectives dominate current thinking about human similarities and differences: an evolutionary perspective, emphasizing how biology and human kinship makes us similar, and a cultural perspective that emphasises how cultural impacts make us diverse. Nearly everyone agrees that we need both: Our genes and inborn qualities and instincts enable an adaptive and developing human brain-a cerebral structure that receives cultural impact and develop and increases its capacity due to its plasticity ability to change both structure and function. Evolutionary psychology has by somebody been looked upon as a modern variant of the deterministic machine paradigm since living species' behaviour, human beings included, is steered by the "selfish gene" only interested to reproduce itself. Intentional or conscious behaviour is an illusion; we are ruled by our genes motive to reproduction when we for instance fall in love. Our psychological makeup, our anxieties, worries and happiness is inherited and determined by the genetic selection process in the past. There is no genetic determinism that can account for all changes in living beings, and the changes in individuals represent a space of freedom before the surviving comes into play to keep some of the creative changes and eliminate others. This is an interesting presentation on how the evolution actually happens, and tells that in the nature (and of course in the culture) there are principles of creativity and indetermination governing and deciding the development processes. First comes the variation in human individuals, either deliberately or accidental, and then the selection. It is possible to create individuals that have a greater possibility to survive and to spread its genes to the next generation and this mechanism has consequences for the content of evolutionary psychology.

\section{The Alternative}

That humans are the creators of psychological reality and that the development of human beings is dialectic and therefore 
cannot be simulated by simple cause-effect understanding, irrespective of the number of causal variable included and how "complex" the model is should be underlined in an alternative epistemology for human beings. Dialectical thought is the opposite of formal logical thought. The inborn abilities make humans different from machines. To be creative in the human way cannot in principle be simulated by a machine. And to "forget" or to omit this ability does not make it possible to understand what a human actually is. Vygotsky's (1990) presentation of creativity and imagination is important to understand human beings, and explains how this ability works together with repetition. Vygotsky presents a dialectic understanding of human development and his focus on the repetitive and the creative, and how humans relate to the cultural context is crucial for understanding of human beings development.

\section{Vygotsky: Higher Psychological Functions}

Vygotsky's (1997) criticism of the dominating schools of psychology at his time was in some ways similar to the criticism today: humans are understood and studied as determined by reflexes, reactions and associations with little room for subjectivity agency and creativity.

His solution was that scientific psychology cannot ignore that human consciousness exists and that it has to be a significant topic in psychology (1997). Humans' higher psychological functions, their language and thinking, have to be the core of human psychology. Humans have many psychological functions in addition to the ones we find in dogs and other living organisms. Most basic is the fact that man not only develops (naturally); he also constructs himself. The number of human activities under biological control is greatly reduced in comparison to animals. Psychological phenomena, including perception, cognition, emotion, memory, psychopathology, personality and malfunctions are humanly constructed as individuals participate in social interaction. This position, that psychology has a constructed character, does not disregard biological influences. Vygotsky (1997) demonstrated the importance of biology for psychology but without dissolving social consciousness into biological processes. This leaves psychological activity as something to be built up from, rather than reduced to, a biological substratum.

\section{The Brain's Plasticity}

Many body functions are dependent on the environment. Production of the hormones adrenalin and noradrenalin will be influenced by how stressful we regard a social situation to be. Other hormones and physiological processes also react to the environment. This dependency of the environment is not unique for Homo sapiens, most living organisms and even elements and physical/chemical substances adjust and are dependent on the environment (Kolstad, 2012).

The structure and functions of the elements and how they relate to each other (their function) cannot be explained without taking the environment into consideration. The combination of Oxygen and Hydrogen has quite different structures (and functions) depending on temperature and pressure. The mixture of the two elements has different states, ice below zero degrees Celsius, water between zero and 100 degrees Celsius, and vapour when the temperature is above 100 degrees Celsius (depending also on the atmospheric pressure). This is an example of a natural phenomenon heavily dependent on the environment. The same is the case for most elements, their structure and functions. Carbon is coal with one molecular structure when established in one environment and diamond with a totally different structure if established under other environmental circumstances and in another inter-functionality. The same element acquires a unique structure and function owing to the impact of other elements and the environment. It also changes structure and function through time. The human brain are no exceptions in this respect, it also adjusts to the environment, the social situation and to our psychological reactions. The brain develops new capacity as a result of our experience, our physical and mental activity and how we cope with the situation. It stores what happens and creates new ways of thinking, feeling and behaving. This quality of the brain is due to its "plasticity", or ability to develop and change. Physical and mental activity produces structural changes in the brain due to the brain plasticity in humans (Kolb \& Whishaw, 1998). Two decades ago the brain was looked upon as anatomically hard-wired at birth. In the past two decades, however, an enormous amount of research has revealed that the brain never stops changing and adjusting. So it is not really legitimate any longer to regard the brain as a fixed collection of wired-up neurons like the hardware in a PC. The interconnections between neurons are changing all the time and brain structure is more like the software. This model explains the importance of social and cultural influences since experiences are internalized and stored both in mind and brain. Norman Doidge stated that neuroplasticity is "one of the most extraordinary discoveries of the twentieth century” (Doidge, 2007).

The human brain is incredibly adaptive, and our ability to process widely varied information and complex new experiences are tremendous. The brain's ability react in an everchanging ways is called it's "neuroplasticity". This characteristic allows the brain's estimated 100 billion nerve cells, to constantly establish new pathways for neural transmission and to rearrange others throughout life. Neuroplasticity is therefore aiding the processes of learning, memory, and adaptation through experience.

Neuroplasticity is not something found only in a single brain structure or consisting of just one type of physical or chemical event. The brain's ability to be molded is the result of many different, complex processes that occurs throughout the lifetime. Different structures and types of cells make neuroplasticity possible.

\section{Genes, Neurobiology and Culture}

So what about genetic factors? The genes make up the structure and immediate function of the brain at birth. But the environment immediately begins to exert its heavy influence on the brain. Every day the newborn's brain is flooded with new information through the sensory organs. The neurons, or brain cells, are responsible for sending that information to the part of the brain best equipped to handle it. This requires that each neuron "knows" the proper pathways. The genes have, at birth, laid down the mental roadmap neurons must follow and built its major "highways" between the basic areas of the brain (Kolstad, 2012). Environmental influence plays the key role in forging a denser and more complex network of interconnections. These smaller avenues and side roads makes the transfer of information between neurons more efficient and rich with situation- 
specific detail. At birth, each neuron has approximately 2500 synapses or connections. By the time we have reached $2-3$ years of age, sensory stimulation and environmental experience have taken full advantage of the brain's plasticity; each neuron now boasts around 15,000 synapses (Gopnick, Meltzoff, \& Kuhl, 1999).This number will have declined somewhat by the time we enter adulthood, as many of the more ineffective or rarely used connections - formed during the early years, when neuroplasticity is at its peak-are done away with.

While genetics certainly play a role in establishing the brain's plasticity, the environment also exerts heavy influence in maintaining it. Take, for example, the newborn's brain, which every day is flooded with new information. When the infant body receives input through its many different sensory organs, neurons are responsible for sending that input back to the part of the brain best equipped to handle it - and this requires each neuron to "know" something about the proper neural pathways through which to send its bits and pieces of information. To make this mental roadmap work, each neuron develops an axon to send information to other brain cells via electrical impulses, and also develops many dendrites that connect it to other neurons so that it can receive information from them.

\section{How Does Neuroplasticity Work?}

Neuroplasticity work in two ways; it deletes old connections between neurons and it enables the creation of new ones. Through "synaptic pruning", connections that are inefficient or infrequently used fade away, while connections between neurons that are highly routed will be preserved and strengthened. Learning new skills and represent experiences may require large collections of neurons to be active simultaneously to process neural information, and the more neurons activated, the better we learn. In response to a new experience or novel information, neuroplasticity allows either an alteration to the structure of already-existing connections between neurons, or forms brand-new connections. The latter leads to increased synaptic density while the former makes existing pathways more efficient or suitable. The brain is remolded to collect and preserve the new data and, if useful, retain it. When we are first exposed to something new, that information enters our shortterm memory, which depends mostly upon chemical and electrical processes known as synaptic transmission to retain information, rather than deeper and more lasting structural changes such as those mentioned above. When we perceive the new information as especially important or when a certain experience is repeated fairly often the structural change in the brain will last and the new information is hard-wired into the neural pathways of the brains These changes result either in an alteration to an existing brain pathway, or in the formation of a new one. Further repetition of the same information or experience may lead to more modifications in the connections that house it, or an increase in the number of connections that can access itagain, as a result of the plasticity

(http://www.thememoryworks.com/neuroplasticity/).

\section{Neurogenesis in Two Parts of the Brain}

The brain never ceases being pruned and it establishes new connections the entire life. Our neural connections do not ever reach, by some age, a fixed pattern that thereafter cannot change. Rather, the ongoing process of synaptic reformation and death is what gives the brain its plasticity, to acquire new knowledge and learn from fresh experiences. New research suggests that, beyond modifying pathways and forming new ones between existing neurons, the human brain also generate entirely new brain cells. While this neural regeneration was long believed to be impossible after age three or four, research now shows that new neurons can develop late into the life span, even of age 70 and beyond. The neurogenesis happens in the olfactory bulb and in Hippocampus. If one's brain is constantly challenged by and engaged with a variety of new experiences, while also exposed regularly to that which it already knows, it is better able to retain its adaptive flexibility, regenerative capacity, and remarkable efficiency throughout life

(http://www.thememoryworks.com/neuroplasticity/).

According to Kempermann, Gast, \& Gage (2002) neurons are continually born from endogenous stem cells and added to the dentate gyrus throughout life. But adult hippocampal neurogenesis declines precipitously with age. Short-term exposure to an enriched environment leads however, to a striking increase in new neurons. Adult hippocampal neurogenesis in mice living in an enriched environment from the age of 10 to 20 months was fivefold higher than in controls. This cellular plasticity occurred in the context of significant improvements of learning parameters, exploratory behavior, and locomotor activity. Enriched living mice also had a decreased nonspecific age-dependent degeneration. Therefore, in mice signs of neuronal aging can be diminished by a sustained active and challenging life, even if this stimulation started only at medium age. Activity exerts not only an acute but also a sustained effect on brain plasticity.

Draganski et al. (2004) states that structure of an adult human brain alter in response to environmental demands. Wholebrain magnetic-resonance imaging visualizes learning-induced plasticity in the brains of people who have learned to juggle. These individuals show a structural change in brain areas that are associated with the processing and storage of complex visual motion. The discovery of an alteration in the brain's macroscopic structure contradicts the traditionally held view that cortical plasticity is associated with functional rather than anatomical changes.

Maguire et al. (2000), who analyzed structural MRIs of the brains of humans with extensive navigation experience, licensed London taxi drivers, and compared with those of control subjects who did not drive taxi found that the posterior hippocampi of taxi drivers were significantly larger relative to those of control subjects. A more anterior hippocampal region was larger in control subjects than in taxi drivers. Hippocampal volume correlated with the amount of time spent as a taxi driver (positively in the posterior and negatively in the anterior hippocampus). These data are in accordance with the idea that the posterior hippocampus stores a spatial representation of the environment and can expand regionally to accommodate elaboration of this representation in people with a high dependence on navigational skills. It seems that there is a capacity for local plastic change in the structure of the healthy adult human brain in response to environmental demands Trachtenberg, Trepel, \& Stryker, (2002) claim that new synapses in the adult cortex are formed to support experience-dependent plasticity. Although the dendritic structure is stable, some spines appear and disappear. Spine lifetimes vary greatly: stable spines, about $50 \%$ of the population, persist for at least a month, whereas the re- 
mainder is present for a few days or less. Serial-section electron microscopy of imaged dendritic segments revealed retrospectively that spine sprouting and retraction are associated with synapse formation and elimination. Experience-dependent plasticity of cortical receptive fields was accompanied by increased synapse turnover. Measurements suggest that sensory experience drives the formation and elimination of synapses and that these changes might underlie adaptive re-modelling of neural circuits.

\section{Cultural Neuroscience}

Everybody is born into a specific, but dynamic culture that cultivates (the latin word for culture) every human being. But what is actually culture? Culture is a term that has been given many meanings. More than 50 years ago Alfred Kloeber and Clyde Kluckhon (1952) presented in their article Culture: A Critical Review of Concepts and Definitions 164 definitions. In psychology culture is most commonly applied as the term for the patterns of knowledge, beliefs and behaviour, or the set of shared attitudes, norms, values, goals and practices that characterize a group. Language and culture have both emerged as means of using symbols to construct social identity. Children acquire language in the same way as they acquire basic cultural norms and values, through interaction with older members of their cultural group.

Not everybody agrees with this definition. Hubert Hermans challenges the idea that a culture is an "entity" or involves "group membership" and suggests that a culture emerges from patterns of meaning between people in dialogue with each other (Hermans, 2001; Adams \& Markus, 2001). There has been and probably still is some confusion between the concepts of "society" and "culture." For most social psychologists, these are distinct concepts. Society usually refers to a clearly bounded group of people whereas culture refers to permeable and plural human capacities and non-genetic human phenomena.

\section{Genes, Evolution and Behaviour}

The universal behaviour that defines human nature arises from our biological similarity and in some way we are all Africans (Shipman, 2003). Researchers studying human origins do not, however, quite agree when and in what shape the homonids left Africa. According to the Multiregional Continuity Model, Homo erectus left Africa 2 mya (million years ago) to become Homo sapiens in different parts of the world (Myers, Abell, Kolstad, \& Sani, 2009). The "Out of Africa Model” claims that Homo sapiens evolved relatively recently in Africa and migrated into other parts of the world to replace other hominid species, including Homo erectus (Johanson, 2001). In response to climate change and the availability of food, those early hominids migrated across Africa into Asia, Europe, the Australian subcontinent and, eventually, the Americas. As they adapted to their new environments, early humans developed differences that, measured on anthropological scales, are relatively recent and superficial. For example, those who stayed in Africa had darker skin pigment, a "sunscreen for the tropics" (Pinker 2002) and those who went far north of the equator evolved lighter skins capable of synthesizing vitamin $\mathrm{D}$ in less direct sunlight.

We were Africans recently enough that "there has not been much time to accumulate many new versions of the genes",
(Steven Pinker, 2002: p. 143). Biologists who study our genes have found that we humans are strikingly similar in genes, like members of one tribe. We may be more numerous than chimpanzees, but chimps are more genetically varied. We also share the majority of our genes with other species, for instance mice (Myers, Abell, Kolstad, \& Sani, 2010).

\section{Thumbs or Language? Biology or Culture?}

Evolutionary biologists have for many years discussed the reason why Homo sapiens became a new species so different from its animal ancestors. Most often they have looked for anatomical or morphological characteristics, for instance the size of the brain, the functional benefits due to bipedalism, i.e. the ability to move on two legs, or the hand with opposable thumb able to seize (Kolstad, 2010). The unique ability to use language and symbolic systems were hardly mentioned by the biologists. Focusing intently on biological changes they do not refer to culture as a cause of selection. Because of this the evolutionary biologists do not analyze the relationship between biological and cultural development (deLima, 1997).

With Homo sapiens and its substantial growth in brain size 200,000 years ago, an accelerated change began and humans developed spoken language, rituals, arts and ability to think. From a biological and anatomical point of view however, we are in principal similar to our ancestors 200,000 years ago. But in a cultural and psychological sense there are such big differences from our ancestors that it cannot be explained by biological adaption (Kolstad, 2010). To explain radical changes in humans the importance of language and other cultural tools have been accepted as a major contribution to human development. The Neanderthals, in many ways similar to Homo sapiens from a biological point of view, did not develop in the same way. They missed the voice-tube and could not develop spoken language. Even if the voice-tube had some biological drawbacks, for instance increased exposure to choking and less effective chewing (Lieberman, 2006), it represented an enormous enhancement in flexibility concerning production of sounds, improvement in communication and in this way represented the start of human beings as we know them today.

\section{How Culture Overrules Biology in Humans}

The cultural-historical tradition in social psychology was founded by the Russian psychologist Lev Vygotsky in the 1920s. He and his Russian colleague Alexander Luria were impressed, and at the same time dissatisfied, with the research on classical conditioning by their fellow countryman Ivan Pavlov. Pavlov studied learning by associations among animals, especially dogs and concluded that the animals become "conditioned" to act in certain ways by the presence of features in our environment. Vygotsky appreciated Pavlov's scientific methods, but he criticized Pavlov and other behaviourists for not studying the most important subject in psychology: the human mind and consciousness. Pavlov's work was, quite literally, "thoughtless". To reveal that animals could be conditioned to learn through associations in their environment did not reveal anything about the specific and most interesting ability in humans; the capability to think, to use a language and to adhere to cultural norms and values.

According to Vygotsky, each individual's consciousness is built from outside through relations with others. When human 
beings participate in social interactions they develop, construct and create their psychological substance, ways of thinking, feeling, remembering, their sensation and perception etc. In this way culture becomes part of a person's nature (Kolstad, 2012). $\mathrm{He}$ distinguished between "lower" or natural psychological functions and "higher" or cultural functions (Van der Veer \& Valsiner, 1991, 1994). The lower functions are biological mechanisms, such as blind reactions to stimuli as we would see in all animals. They do not involve conscious experience. Over time, these lower functions are transformed, and are controlled by higher "cultural" functions. These higher psychological functions actually stimulate neuronal growth in particular directions and create their own biological mediations, restructuring the brain (Vygotsky, 1986; Wertsch, 2008).

This position does not leave out biological factors or disregard biological influences. According to cultural-historical psychology, biological phenomena provide the framework for mental phenomena rather than directly determining them. This leaves psychological activity as something to be built up from, rather than reduced to biology. To be human means that you have surpassed a level of functioning that your biological traits would otherwise dictate (Van der Veer \& van Uzendoorn, 1985).

But if human psychology is socially and cultural determined, does this mean that the individual is reduced to an automaton that passively receives social influences? Quite the contrary: "The child begins to see the external world not simply with his eye as a perceiving and conducting apparatus - the child sees with all of his previous experience...” (Vygotsky \& Luria, 1993: p. 148). Culture does not simply regulate natural processes; it supercedes lower elementary processes and forms the entire content of psychological phenomena (Ratner, 1994).

Perhaps our most important similarity, the hallmark of our species, is our capacity to use psychological tools like language. Evolution has prepared us to talk and acquire signs and symbols from a culture and make them our own. Compared with other animals, nature has humans on a looser genetic leash. The genetic or instinctive driving forces are overruled by what is acquired during socialization. Our biology and especially our brain, developed through evolution and made thinking and language appropriation possible (Kolstad, 2012).

We humans have been selected not just for our big brains and biceps but also for our culture. We come prepared to learn language and to bond and cooperate with others in securing food, caring for young, and protecting ourselves. Nature therefore predisposes us to learn, whatever culture we are born into (Fiske et al., 1998). The cultural perspective, while acknowledging that all behaviour requires our evolved genes, highlights human development and socialization. People's "natures are alike", said Confucius; "it is their habits that carry them far apart”.

\section{Cultural Diversity}

The diversity of our languages, customs, and expressive behaviors confirms that much of our behaviour is socially and culturally programmed, not hardwired. Humans, more than any other animal, harness the power of culture to make life better. We have culture to thank for our communication through language. Culture facilitates our survival and reproduction, and nature has blessed us with a brain that, like no other, enables culture. No species can accumulate progress across generations as smartly as humans due, amongst other things, to the invention of written language. We can pass our experiences and transmit information and innovations across time and place to the future generations in a unique way.

We needn't think of evolution and culture as competitors. Cultural norms subtly but powerfully affect our attitudes and behaviour, but they don't do so independent of biology. Advances in genetic science indicate how experience and activity change the brain and establish new connections between neurons (Quarts \& Sejnowski, 2002). Our brain develops and increases its capacity due to its plasticity.

\section{REFERENCES}

Adams, G., \& Markus, H. R. (2001). Culture as patterns. An alternative approach to the problem of reification. Culture \& Psychology, 7, 289-296. doi:10.1177/1354067X0173002

CHI Conference (2009). Guide to a successful HCI archive submission. URL (last checked 15 May 2009).

http://www.chi2009.org/Authors/Guides/ArchiveGuide.html

Cohn, E., \& Geske, T. (1990). The economics of education. New York: The Free Press, 159-210.

Comte, A. (1853/2009). The positive philosophy of Auguste Comte. Cambridge: Cambridge University Press.

deLima, S. G. (1997). Will adding halves make a whole? Comments on Ratners “Activity as a Key Concept for Cultural Psychology”. Culture and Psychology, 3, 195-210.

Doidge, N. (2007). The brain that changes itself. New York: Viking.

Draganski, B., Gaser, C., Busch, V., Schuierer, G., Bogdahn, U., \& May, A. (2004). Neuroplasticity: Changes in grey matter induced by training. Nature, 427, 311-312. doi:10.1038/427311a

Fisher, H. E., Aron, A., \& Brown, L. L. (2006). Romantic love: A mammalian brain system for mate choice. Philosophical Transactions of the Royal Society: Biological Sciences, 361, 2173-2186. doi:10.1098/rstb.2006.1938

Fiske, A. P., Kitayama, S., Markus, H. R., \& Nisbett, R. E. (1998). The cultural matrix of social psychology. In D. T. Gilbert, S. T. Fiske, \& G. Lindzey (Eds.), Handbook of social psychology (pp. 915-981). New York: McGraw-Hill.

Giambastiani, B. M. S. (2007). Evoluzione idrologica ed idrogeologica della pineta di San Vitale (Ravenna). Ph.D. Thesis, Bologna: Bologna University.

Gopnick, A., Meltzoff, A., \& Kuhl, P. (1999). The scientist in the crib: What early learning tells us about the mind. New York: Harper Collins Publishers.

Grudin, J. (1990). The computer reaches out: The historical continuity of interface design. Proceedings of the SIGCHI Conference on $\mathrm{Hu}$ man Factors in Computing Systems: Empowering People. New York: ACM Press, 261-268.

Gusnard, D. A., Akbudak, E., Shulman, G. L., \& Raichle, M. E. (2001). Medial prefrontal cortex and self-referential mental activity: Relation to a default mode of brain function. Proceedings of the National Academy of Sciences of the United States of America, 98, 4259-4264. doi:10.1073/pnas.071043098

Helfer, M. E., Keme, R. S., \& Drugman, R. D. (1997). The battered child (5th ed.). Chicago, IL: University of Chicago Press.

Hermans, H. J. M. (2001). The dialogical self: Toward a theory of personal and cultural positioning. Culture \& Psychology, 7, 243-281. doi:10.1177/1354067X0173001

Johanson, D. (2001). Origins of modern humans: Multiregional or out of Africa? URL (last checked 26 November 2009). http://www.actionbioscience.org/evolution/johanson.html

Kempermann, G. (2002). Why new neurons? Possible functions for adult hippocampal neurogenesis. Journal of Neuroscience, 22, 635638.

Kempermann, G., Gast, D., \& Gage, F. H. (2002). Neuroplasticity in old age: Sustained fivefold induction of hippocampal neurogenesis by long-term environmental enrichment. Annals of Neurology, 52, 


\section{A. KOLSTAD}

135-143. doi:10.1002/ana.10262

Kloeber, A., \& Kluckhon, C. (1952). Culture: A critical review of concepts and definitions. New York: Randon House.

Kohler, A. (2010). To think human out of the machine paradigm: Homo Ex Machina. Integrative Psychology and Behavioral Science, 44, 39-57. doi:10.1007/s12124-010-9113-z

Kolb, B., \& Whishaw, I. Q. (1998). Brain plasticity and behavior. Annual Reviews of Psychology, 49, 43-64. doi:10.1146/annurev.psych.49.1.43

Kolstad, A. (2010). Time for paradigmatic substitution in psychology. What are the alternatives? Integrative Psychology and Behavioral Science, 44, 58-64. doi:10.1007/s12124-010-9114-y

Kolstad, A. (2012). Inter-functionality between mind, biology and culture: Some epistemological issues concerning human psychologycal development. In M. L. Seidl de Moura (Ed.), Human development-Different perspectives (pp. 19-41). Rijeka: InTech.

Lieberman, A. F., \& Amaya-Jackson, L. (2005). Reciprocal influences of attachment and trauma: Using a dual lens in the assessment and treatment in infants, toddlers, and preschoolers. In L. Berlin, Y. Ziv, L. Amaya-Jackson, \& M. T. Greenberg (Eds.), Enhancing early attachments: Theory, research, intervention, and policy (pp. 120-126). New York: Guilford Press.

Lieberman, P. (2006). The evolution of human speech its anatomical and neural bases. Current Anthropology, 48, 39-66.

Maguire, E. A., Gadian, D. G., Johnsrude, I. S., Good, C. D., Ashburner, J., Frackowiak, R. S. et al. (2000). Navigation-related structural change in the hippocampi of taxi drivers. Proceedings of the $\mathrm{Na}$ tional Academy of Sciences of the United States of America, 97, 4398-4403. doi:10.1073/pnas.070039597

Marcinkowski, T. J., \& Rehring, L. (1995). The secondary school report: A final report on the development, pilot testing, validation, and field testing of the secondary school environmental literacy assessment instrument. Cincinnati, $\mathrm{OH}$ : US Environmental Protection Agency.
Myers, D., Abell, J., Kolstad, A., \& Sani, F. (2010). Social psychology. New York: McGraw Hill.

Pinker, S. (2002) The blank slate: The modern denial of human nature. London: Penguin.

Quartz, S. R., \& Sejnowski, T. J. (2002). The neural basis of cognitive development: About how we become who we are. New York: HarperCollins.

Ratner, C. (2012). Macro-cultural psychology. In J. Valsiner (Ed.), Oxford handbook of culture and psychology. Oxford: Oxford University Press.

Shipman, P. (2003). We are all Africans. American Scientist Online.

Trachtenberg, J. T., Trepel, C., \& Stryker, M. P. (2000). Rapid extragranular plasticity in the absence of thalamocortical plasticity in the developing primary visual cortex. Science, 287, 2029-2032. doi:10.1126/science.287.5460.2029

Van der Veer, R., \& van Uzendoorn, M. H. (1985). Vygotsky’s theory of the higher psychological processes: Some criticisms. Human Development, 28, 1-9. doi:10.1159/000272931

Van der Veer, R., \& Valsiner, J. (1991). Understanding vygotsky: A quest for synthesis. Cambridge: Blackwell.

Van der Veer, R., \& Valsiner, J. (1994). The vygotsky reader. Cambridge: Blackwell.

Vygotsky, L. (1986). Thought and language. Oxford: Blackwell.

Vygotsky, L. S. (1990). Imagination and creativity in childhood. Soviet Psychology, 28, 84-96.

Vygotsky, L. S. (1997). The history of the development of higher mental functions. In R. W. Rieber (Ed.), The collected works of L. S. Vygotsky (pp. 1-252). New York: Plenum.

Vygotsky, L., \& Luria, A. (1993). Studies on the history of behavior. Ape, primitive, and child. Hillsdale, NJ: Erlbaum.

Wertsch, J. V. (1985). Vygotsky and the social formation of mind. Cambridge, MA: Harvard University Press.

http://www.thememoryworks.com/neuroplasticity/ 